\title{
Analisis Faktor-Faktor Yang Mempengaruhi Efektivtas Kelompok Tani Kopi Arabika Di Kecamatan Sangir Kabupaten Solok Selatan
}

\author{
Joni Pardilo, Asmawi, Zulvera \\ Program Pasca Sarjana Universitas Andalas, Indonesia \\ e-mail: pardilojp@gmail.com
}

\begin{abstract}
Abstrak
Tujuan penelitian ini untuk mengetahui 1) Sejauhmana tingkat efektivitas kelompok tani kopi Arabika di Kecamatan Sangir Kabupaten Solok Selatan. 2) Sejauhmana pengaruh faktor internal terhadap efektivitas kelompok tani kopi Arabika di Kecamatan Sangir Kabupaten Solok Selatan. 3) Sejauhmana pengaruh faktor eksternal terhadap efektivitas kelompok tani kopi Arabika di Kecamatan Sangir Kabupaten Solok Selatan. Populasi dalam penelitian ini adalah petani yang menjadi anggota kelompok tani yang berusaha tani kopi Arabika di Kecamatan Sangir, Sampel dihitung menggunakan rumus slovins dengan jumlah sebanyak 117 orang.

Berdasarkan hasil analisis dan pembahasan, maka dapat dibuat beberapa kesimpulan sebagai berikut 1) Gingkat efektivitas kelompok tani kopi kopi arabika di kecamatan sangir kabupaten solok selatan dapat dilihat dari petama produktvitas kelompok, dimana secara kesleuruhan dilaksanakan dengan cukup efektif sehingga terlihat bahwa anggota kelompok tani tersebut saling membantu anggotanya agar usaha taninya berkembang. Kedua Kepuasan anggota, secara keseluruhan dilaksanakan dengan cukup efektif sehingga terlihat bahwa anggota kelompok tani tersebut dapat menikmati peran mereka masing-masing sebagai anggota kelompok maupun peran dan fungsi kelompok dalam menunjang kebutuhan serta menyelesaikan masalah dalam berusaha tani kopi. Berdasarkan hasil analisis ditemukan faktor internal kelompok berpengaruh positif dan signifikan terhadap efektivitas kelompok tani kopi arabika di Kecamatan Sangir Kabupaten Solok Selatan.
\end{abstract}

Keywords: Faktor Internal Kelompok, Faktor Eksternal Kelompok, Efektivitas Kelompok

\section{Abstract}

The purpose of this study was to determine 1) How far the level of effectiveness of Arabica coffee farmer groups in Sangir Subdistrict, South Solok Regency. 2) How far the influence of internal factors on the effectiveness of Arabica coffee farmer groups in Sangir Subdistrict, South Solok Regency. 3) How far the influence of external factors on the effectiveness of Arabica coffee farmer groups in Sangir Subdistrict, South Solok Regency. The population in this study are farmers who are members of farmer groups who are trying to grow Arabica coffee in Sangir District, Samples were calculated using the slovins formula with a total of 117 people.

Based on the results of the analysis and discussion, a number of conclusions can be made as follows 1) The effectiveness of the Arabica coffee farmer groups in Sangir Selatan, Solok Selatan subdistrict can be seen from the first group productivity, which is carried out effectively enough so that it appears that members of the farmer groups are mutually help its members to grow their farming business. Second, member satisfaction, as a whole is carried out effectively enough so that it appears that members of the farmer group can enjoy their respective roles as group members and the role and function of the group in supporting needs and solving problems in trying to farm coffee. Based on the results of the analysis, it was found that the internal factors of the group had a positive and significant effect on the effectiveness of the Arabica coffee farmer group in Sangir Subdistrict, South Solok Regency.

Kata Kunci : Internal Group Factors, Group External Factors, Group Effectiveness 


\section{PENDAHULUAN}

Indonesia adalah produsen kopi terbesar keempat di dunia setelah Brazil,Vietnam dan Colombia dengan menyumbang sekitar 7,27\% dari produksi total kopi dunia secara rinci dapat dilihat pada lampiran 1 dan Indonesia merupakan pengekspor kopi terbesar keempat di dunia dengan pangsa pasar sekitar 7,41\% seperti terlihat pada lampiran 2 (Pusdatin, 2018). Provinsi Sumatera Barat yang merupakan penghasil kopi Arabika keempat di Indonesia. Produksi kopi Arabika Sumatera Barat tahun 2013-2017 mencapai rata-rata 15,11 ribu ton atau berkontribusi sebesar 9,40\% dari total produksi kopi Indonesia. Potensi kopi di Provinsi Sumatera Barat tersebar di beberapa daerah diantaranya; Kabupaten Solok Selatan berkontribusi hingga 28,90\% dari total produksi Arabika Sumatera Barat, berikutnya Kabupaten Pasaman 15,33\%. Kemudian tiga Kabupaten lainnya adalah Pesisir Selatan, Solok dan Kabupaten Lima Puluh Kota dengan produksi secara berturut-turut yaitu 12,79\%, 11,58\% dan 9,03\%, total produksi kopi Arabika Propinsi Sumatera Barat pada tahun 2015 sebesar 15,13 ribu ton, secara rinci ditampilkan pada lampiran 4 (Pusdatin, 2017).

Kabupaten Solok Selatan merupakan salah satu Kabupaten penghasil kopi Arabika terbesar di Sumatera Barat. Perkebunan kopi Arabika di Kabupaten Solok Selatan dengan luas 306 Ha yang tersebar pada tiga Kecamatan antaranya ; Kecamatan Sangir 280 Ha, Kecamatan Pauh Duo 17 Ha dan Koto Parik Gadang Diateh 9 Ha, secara lengkap ditampilkan pada tabel 1.

Tabel. 1 Data Daerah Sentra kopi Arabika Kabupaten Solok Selatan

\begin{tabular}{lcc}
\hline \multicolumn{1}{c}{$\begin{array}{c}\text { Kecamatan/ } \\
\text { Sudistric }\end{array}$} & $\begin{array}{c}\text { Luas Arabika } \\
\text { Luas/Area (Ha) }\end{array}$ & $\begin{array}{c}\text { Produksi/ } \\
\text { Production (Kg) }\end{array}$ \\
\hline Sangir & 280 & 224.052 \\
Sangir Jujuan & - & - \\
Sangir Balai janggo Sangir Batang Hari & - & - \\
Sungai Pagu & - & - \\
Pauh Duo & - & - \\
Koto Parik Gadang Diateh & 17 & 9.684 \\
& 9 & 4.140 \\
\hline Jumlah & 306 & 237.876 \\
\hline
\end{tabular}

Sumber : Data Badan Pusat Statistik Solok Selatan dalam Angka Tahun 2018

Kementerian Pertanian juga menyatakan bahwa dengan bergabungnya petani dalam wadah kelompok tani dapat membantu menggali potensi, memecahkan masalah usahatani anggotanya, memudahkan mengakses informasi, pasar, teknologi, permodalan dan sumberdaya lainnya. Dengan demikian kelompok tani memiliki kedudukan yang strategis di dalam mewujudkan petani yang berkualitas. Petani yang berkualitas antara lain dicirikan oleh adanya kemandirian dan ketangguhan dalam berusahatani (Kementan, 2017).

Kabupaten Solok Selatan merupakan salah satu daerah yang memiliki potensi untuk dikembangkan perkebunan kopi Arabika terutama di Kecamatan Sangir. Pada kawasan pengembangan kopi Arabika petani telah bergabung kepada beberapa kelompok tani. Kelompok tani yang melakukan budidaya kopi Arabika sebanyak 10 (Sepuluh) kelompok tani terdiri dua kelas kemampuan kelompok diantaranya; kelas pemula 8 (delapan) dan lanjut 2 (dua) kelompok.

Adapun kegiatan untuk meningkatkan kemampuan kelompok-kelompok tersebut yaitu berupa pemberian pelatihan dan ketrampilan bagi penyuluh pertanian lapangan, pelaksana penyuluhan dan latihan bagi petani melalui kelompok tani maupun perorangan; dan memotivasi bagi penguatan kelembagaan petani kearah kemandirian kelompok, ketangguhan kelompok, dan kemitraan usaha. Tujuan yang hendak dicapai adalah peningkatan sumberdaya pelaku usaha pertanian menjadi sumberdaya yang 
tangguh, terampil, dan mandiri, optimalisasi pemanfaatan sumberdaya yang dapat memberikan nilai tambah melalui penerapan teknologi dan berwawasan lingkungan; meningkatan pelayanan dibidang pertanian; dan memantapkan kelembagaan tani melalui pembinaan dan peningkatan kelas kelompok. Namun berdasarkan observasi awal kelihatan kelompok-kelompok tani tersebut masih belum menunjukkan efektivitas kelompoknya.

Tujuan penelitian ini adalah untuk mengetahui secara deskriptif tentang; (1) tingkat efektivitas kelompok tani kopi Arabika di Kecamatan Sangir Kabupaten Solok Selatan; (2) Menganalisis pengaruh faktor internal dengan efektivitas kelompok tani kopi Arabika di Kecamatan Sangir Kabupaten Solok Selatan; (3)Menganalisis pengaruh faktor eksternal dengan efektivitas kelompok tani kopi Arabika di Kecamatan Sangir Kabupaten Solok Selatan.

\section{METODE}

Metode penelitian yang digunakan adalah motode survei, yaitu penelitian yang mengambil sampel dari satu populasi dan menggunakan kuisioner sebagai alat pengumpulan data yang pokok. Populasi dalam penelitian ini adalah petani yang menjadi anggota kelompok tani yang berusaha tani kopi Arabika di Kecamatan Sangir. Kelompok-kelompok yang melakukan usaha kopi Arabika di Kecamatan Sangir yaitu sebanyak 10 (sepuluh) kelompok tani, sehingga dengan demikian total populasi pada penelitian ini sebanyak 166 orang tergabung dalam 10 kelompok tani. Penentuan jumlah anggota kelompok yang dijadikan sebagai sampel dihitung dengan menggunakan rumus Slovins dalam Siregar (2012).

$$
\begin{aligned}
& n=\frac{N}{1+N e^{2}} \\
& n=\frac{166}{1+166\left(0,05^{2}\right)}=117
\end{aligned}
$$

Keterangan :

$$
\begin{array}{ll}
\mathrm{n} & =\text { Ukuran sampel } \\
\mathrm{N} & =\text { Populasi } \\
\mathrm{e} & =\text { Margin of error (pada penelitian ini ditetapkan }(0,05)
\end{array}
$$

Tabel. 3 Kelompok dan Responden yang diteliti

\begin{tabular}{clcc}
\hline No & \multicolumn{1}{c}{ Nama Kelompok } & Jumlah Anggota & Responden \\
\hline 1. & Camintoran Sepakat & 23 & 16 \\
2. & Sumber Rezeki & 18 & 13 \\
3. & Umbul Mulyo & 9 & 6 \\
4. & Sinar Paninjauan & 14 & 10 \\
5. & Pemuda sejahtera & 18 & 13 \\
6 & Letter W & 22 & 16 \\
7 & Durita Sejahtera & 11 & 8 \\
8 & Pemuda harapan & 18 & 13 \\
9 & Sinar jaya & 16 & 11 \\
10 & Harapan baru & 17 & 11 \\
\hline & Jumlah & $\mathbf{1 6 6}$ & $\mathbf{1 1 7}$ \\
\hline
\end{tabular}

Rumus yang digunakan untuk uji validitas konstruk dengan teknik korelasi produck moment

$$
\text { Ir hitung }=\frac{n\left(\sum X Y\right)-\left(\sum X\right)\left(\sum Y\right)}{\sqrt{ }\left(n\left(\sum X^{2}\right)-\left(\sum X\right)^{2}\left(n\left(\sum Y^{2}\right)-\left(\sum Y\right)^{2}\right.\right.}
$$




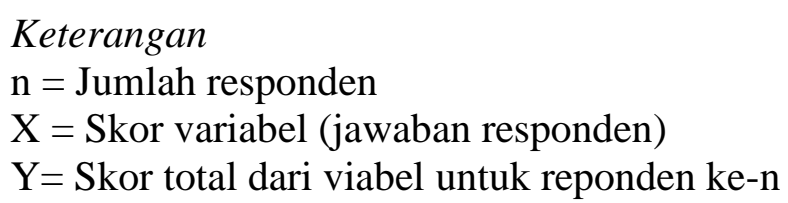

Analisis data yang digunakan pada penelitian ini adalah analisis deskriptif kuantitatif. Analisis data kuantitatif mengikuti tahap-tahap analisis data kuantitatif. Metode analisis data yang digunakan dalam penelitian ini adalah analisis deskriptif kuantitatif digunakan untuk menjawab tujuan penelitian pertama, yakni dengan menggunakan model distribusi frekuensi (Siregar, 2017).

\section{HASIL DAN PEMBAHASAN}

\section{Hasil Penelitian}

Tabel. 6 Hasil Uji Validitas Faktor Internal Kelompok

\begin{tabular}{|c|c|c|c|c|c|}
\hline No & Item Pernyataan & $\begin{array}{c}\text { corrected } \\
\text { item total } \\
\text { corelation } \\
\text { Tahap I }\end{array}$ & Ket & $\begin{array}{c}\text { corrected } \\
\text { item total } \\
\text { corelation } \\
\text { Tahap II }\end{array}$ & Ket \\
\hline 1 & Usia & $-0,198$ & Tidak Valid & & - \\
\hline 2 & $\begin{array}{l}\text { tingkat pendidikan } \\
\text { formal }\end{array}$ & $-0,046$ & Tidak Valid & & - \\
\hline 3 & $\begin{array}{l}\text { frekuensi pendidikan } \\
\text { non formal }\end{array}$ & 0,527 & Valid & 0,575 & Valid \\
\hline 4 & $\begin{array}{l}\text { pengalaman usaha } \\
\text { tani }\end{array}$ & 0,365 & Valid & 0,338 & Valid \\
\hline 5 & luas lahan & 0,352 & Valid & 0,333 & Valid \\
\hline 6 & $\begin{array}{l}\text { kekosmopolitan } \\
\text { a. kekosmopolitan } 8 \\
\text { b. kekosmopolitan } 9 \\
\text { c. kekosmopolitan } 10 \\
\text { d. kekosmopolitan } 11 \\
\text { e. kekosmopolitan } 12\end{array}$ & $\begin{array}{l}0,246 \\
0,415 \\
0,411 \\
0,396 \\
0,394 \\
\end{array}$ & $\begin{array}{c}\text { Tidak Valid } \\
\text { Valid } \\
\text { Valid } \\
\text { Valid } \\
\text { Valid }\end{array}$ & $\begin{array}{l}0,495 \\
0,467 \\
0,383 \\
0,338 \\
\end{array}$ & $\begin{array}{l}- \\
\text { Valid } \\
\text { Valid } \\
\text { Valid } \\
\text { Valid }\end{array}$ \\
\hline
\end{tabular}

Sumber : Data primer diolah, 2020

Dari Tabel 6 dapat dijelaskan bahwa 10 butir item pertanyaan untuk faktor internal kelompok tiga diantaranya tidak valid yaitu mengenai usia, tingkat pendidikan formal dan pertanyaan kekosmopolitan 8 sehingga dikeluarkan dan setelah diulang 7 item pernyataan tersisa seluruhnya dinyatakan valid karena memiliki nilai corrected item-total correlation lebih besar dari 0,30 seperti yang dikemukakan Sugiyono (2012), sehingga item pernyataan yang valid dapat dijadikan acuan untuk analisis selanjutnya. 
Tabel. 7 Hasil Uji Validitas Faktor Eksternal Kelompok

\begin{tabular}{|c|c|c|c|}
\hline No & Item Pernyataan & $\begin{array}{c}\text { corrected item total } \\
\text { corelation }\end{array}$ & Keterangan \\
\hline \multirow[t]{4}{*}{1} & ketersediaan informasi & & \\
\hline & ketersediaan informasi 1 & 0,375 & Valid \\
\hline & ketersediaan informasi 2 & 0,384 & Valid \\
\hline & ketersediaan informasi 3 & 0,306 & Valid \\
\hline \multirow[t]{4}{*}{2} & ketersediaan saprodi & & \\
\hline & ketersediaan saprodi 4 & 0,698 & Valid \\
\hline & ketersediaan saprodi 5 & 0,583 & Valid \\
\hline & ketersediaan saprodi 6 & 0,366 & Valid \\
\hline \multirow[t]{5}{*}{3} & ketersediaan modal & & \\
\hline & ketersediaan modal 7 & 0,393 & Valid \\
\hline & ketersediaan modal 8 & 0,677 & Valid \\
\hline & ketersediaan modal 9 & 0,565 & Valid \\
\hline & ketersediaan modal 10 & 0,714 & Valid \\
\hline \multirow[t]{4}{*}{4} & intensitas penyuluhan & & \\
\hline & intensitas penyuluhan 11 & 0,411 & Valid \\
\hline & intensitas penyuluhan 12 & 0,372 & Valid \\
\hline & intensitas penyuluhan 13 & 0,442 & Valid \\
\hline \multirow[t]{5}{*}{5} & kepemimpinan ketua kelompok & & \\
\hline & kepemimpinan ketua kelompok 14 & 0,595 & Valid \\
\hline & kepemimpinan ketua kelompok 15 & 0,438 & Valid \\
\hline & kepemimpinan ketua kelompok 16 & 0,478 & Valid \\
\hline & kepemimpinan ketua kelompok 17 & 0,595 & Valid \\
\hline \multirow[t]{3}{*}{6} & kemudahan pemasaran hasil pertanian & & \\
\hline & kemudahan pemasaran hasil pertanian 18 & 0,304 & Valid \\
\hline & kemudahan pemasaran hasil pertanian 19 & 0,336 & Valid \\
\hline
\end{tabular}

Sumber : Data primer diolah, 2020

Tabel. 8 Hasil Uji Validitas Faktor Eksternal Kelompok

\begin{tabular}{clcl}
\hline No & \multicolumn{1}{c}{ Item Pernyataan } & $\begin{array}{c}\text { corrected item } \\
\text { total corelation }\end{array}$ & Keterangan \\
\hline $\mathbf{1}$ & produktivitas kelompok & & \\
& produktivitas kelompok 20 & 0,763 & Valid \\
& produktivitas kelompok 21 & 0,410 & Valid \\
& produktivitas kelompok 22 & 0,682 & Valid \\
\hline $\mathbf{2}$ & kepuasan anggota & & \\
& kepuasan anggota 23 & 0,599 & Valid \\
& kepuasan anggota 24 & 0,555 & Valid \\
& kepuasan anggota 25 & 0,698 & Valid \\
\hline
\end{tabular}

Sumber : Data primer diolah, 2020

Dari Tabel 8 berikut dapat dijelaskan bahwa 6 butir item pertanyaan untuk efektivitas kelompok seluruhnya dinyatakan valid karena memiliki nilai corrected item-total correlation lebih besar dari 0,30 seperti yang dikemukakan Sugiyono (2012), sehingga item pernyataan yang valid dapat dijadikan acuan untuk analisis selanjutnya. 
Tabel $10 \quad$ Faktor Internal Kelompok yang Mempengaruhi Efektivitas Kelompok Tani Kopi Arabika Di Kecamatan Sangir

\begin{tabular}{|c|c|c|c|}
\hline No & Faktor Internal & Frekuensi & Persentase \\
\hline \multirow[t]{4}{*}{1} & Usia & & \\
\hline & a. Lansia $\geq 65$ tahun & - & - \\
\hline & b. Tua $=55-64$ tahun & 38 & 32,5 \\
\hline & c. Dewasa $<24-54$ tahun & 79 & 67,5 \\
\hline \multirow[t]{4}{*}{2} & Tingkat Pendidikan Formal & & \\
\hline & a. $\quad$ Rendah $=\mathrm{SD}$ & 24 & 20,5 \\
\hline & b. $\quad$ Sedang $=$ SLTP - SLTA & 93 & 79,5 \\
\hline & c. Tinggi $=\mathrm{PT}$ & - & - \\
\hline \multirow[t]{4}{*}{3} & Frekuensi Pendidikan Non Formal & & \\
\hline & a. Rendah $=$ Tidak Pernah & 4 & 3,4 \\
\hline & b. Sedang $=1-2$ kali & 105 & 89,7 \\
\hline & c. Tingi $=>2$ kali & 8 & 6,8 \\
\hline \multirow[t]{4}{*}{4} & Pengalaman Usaha Tani & & \\
\hline & a. $\quad$ Sedikit $=<4$ tahun & 4 & 3,4 \\
\hline & b. Sedang $=5-8$ tahun & 66 & 56,4 \\
\hline & c. Lama $=>8$ tahun & 47 & 40,2 \\
\hline \multirow[t]{4}{*}{5} & Luas Lahan & & \\
\hline & a. Sempit $=<0,5 \mathrm{Ha}$ & 28 & 23,9 \\
\hline & b. Sedang $=0,6-0,9 \mathrm{Ha}$ & 82 & 70,1 \\
\hline & c. Luas $=>1 \mathrm{Ha}$ & 7 & 6,0 \\
\hline \multirow[t]{5}{*}{6} & Kekosmopolitan & & \\
\hline & $\begin{array}{l}\text { kekosmopolitan } 9 \text { ( berapa kali ko } \\
\text { tentang usaha tani kopi dalam satu bul }\end{array}$ & ngan deng & ani luar desa \\
\hline & a. Tidak Pernah & 11 & 9.4 \\
\hline & b. Jarang (hanya 1 kali) & 66 & 56.4 \\
\hline & c. Sering (lebih $>2$ kali) & 40 & 34.2 \\
\hline
\end{tabular}
kekosmopolitan 10 ( berapa kali melakukan kunjungan ke daerah luar / daerah perkebunan kopi dalam waktu enam bulan terakhir untuk meningkatkan usaha tani )
a. Tidak Pernah
5
4.3
b. Jarang (hanya 1 kali)
67
57.3
c. Sering (lebih > 2 kali)
45
38.5

kekosmopolitan 11 ( berapa kali membaca media cetak seperti majalah , brosur, leaflet yang berhubungan dengan pertanian satu bulan terakhir )
a. Tidak Pernah
5
4.3
b. Jarang (hanya 1 kali)
79
67.5
c. Sering (lebih > 2 kali)
33
28.2

kekosmopolitan 12 ( berapa kali mendengarkan / melihat siaran radio/televise yang berhubungan dengan pertanian dalam satu bulan )
a. Tidak Pernah
4
b. Jarang (hanya 1 kali)
74
63.2
c. Sering (lebih $>2$ kali)
39
33.3

Sumber : Data primer diolah, 2020 


\section{Tabel 11 Faktor Eksternal Kelompok (Ketersediaan Informasi)}

\begin{tabular}{llcc}
\hline No. & \multicolumn{1}{c}{$\begin{array}{c}\text { Faktor Eksternal } \\
\text { (Ketersediaan Informasi) }\end{array}$} & Frekuensi & Persentase \\
\hline 1 & Tersedia secara berkala dikelompok tani & & \\
& a. Tidak Pernah Tersedia & 4 & 3.4 \\
& b. Cukup Tersedia & 78 & 66.7 \\
& c. Sangat Tersedia & 35 & 29.9 \\
\hline 2 & Tersedia secara insidentil di kelompok & & \\
& a. Tidak Pernah Tersedia & 12 & 10.3 \\
& b. Cukup Tersedia & 71 & 60.7 \\
& c. Sangat Tersedia & 34 & 29.1 \\
\hline 3 & Tersedia setiap saat dikelompok tani & & \\
& a. Tidak Pernah Tersedia & 27 & 23.1 \\
& b. Cukup Tersedia & 70 & 59.8 \\
& c. Sangat Tersedia & 20 & 17.1 \\
\hline
\end{tabular}

Sumber : Data primer diolah, 2020

Berdasarkan Tabel 11 memperlihatkan bahwa pada umumnya petani yang menjadi anggota kelompok tani kopi Arabika di Kecamatan Sangir mengatakan secara keseluruhan ketersediaan informasi yang berhubungan dengan usaha tani cukup tersedia. Ketersediaan informasi tersebut berkaitan dengan tersedia secara berkala dikelompok tani yang dijawab responden sebanyak 78 orang dengan persentase $66,7 \%$, kemudian ketersediaan informasi tersedia secara insidentil di kelompok dijawab responden sebanyak 71 orang dengan persentase $60,7 \%$, selanjutnya ketersediaan informasi tersedia setiap saat dikelompok tani dijawab responden sebanyak 70 orang dengan persentase $59,8 \%$.

Mugi (2011) mengatakan pada dasarnya ketersediaan informasi merupakan sumberdaya yang penting dalam pertanian. Ketersediaan informasi memegang peranan penting dalam membuka wawasan berpikir petani terhadap dunia nyata yang dialaminya. Sejumlah informasi yang diterima petani akan mengubah konsep-konsep yang ada dalam diri petani tersebut, kemudian membentuk suatu konsep baru yang merupakan penyesuaian informasi lama dengan sejumlah informasi baru yang diterima petani tersebut.

Tabel 12 Faktor Eksternal Kelompok (Ketersediaan Saprodi)

\begin{tabular}{llcc}
\hline No. & \multicolumn{1}{c}{$\begin{array}{c}\text { Faktor Eksternal } \\
\text { (Ketersediaan Saprodi) }\end{array}$} & Frekuensi & Persentase \\
\hline 1 & \multicolumn{4}{l}{ Pendapat mengenai kebutuhan pupuk tersedia sesuai dengan kebutuhan usaha tani } \\
& a. Tidak Tersedia & 59 & 50.4 \\
& b. $\quad$ Cukup Tersedia & 38 & 32.5 \\
& c. $\quad$ Tersedia Sesuai Kebutuhan & 20 & 17.1 \\
\hline 2 & Pendapat mengenai pemenuhan kebutuhan akan bibit ungggul (kopi) & \\
& a. Tidak Pernah Tersedia & 47 & 40.2 \\
& b. Kadang-Kadang Tersedia & 55 & 47.0 \\
& c. $\quad$ Bibit Tersedia & 15 & 12.8 \\
\hline 3 & Pendapat mengenai ketersediaan alat pengolahan pasca panen kopi & \\
& a. Tidak Tersedia & 11 & 9.4 \\
& b. Tersedia Sebahagian & 62 & 53.0 \\
& c. Sangat Tersedia & 44 & 37.6 \\
\hline
\end{tabular}

Sumber : Data primer diolah, 2020 
Berdasarkan Tabel 12 memperlihatkan bahwa pada umumnya petani yang menjadi anggota kelompok tani kopi Arabika di Kecamatan Sangir berpendapat kebutuhan pupuk tidak tersedia sesuai dengan kebutuhan usaha tani sebanyak 59 orang dengan persentase 50,4\%. Hal ini dapat diartikan bahwa ketersediaan pupuk tergolong rendah, pendapat tersebut diungkapkan karena ketersediaan pupuk belum disediakan secara maksimal sehingga tidak mampu mencukupi kebutuhan usaha petani kopi arabika tersebut.

Berdasarkan hasil analisis ditemukan faktor internal kelompok berpengaruh positif dan signifikan terhadap efektivitas kelompok tani kopi arabika di Kecamatan Sangir Kabupaten Solok Selatan. Faktor internal kelompok yang dipergunakan adalah mengenai frekuensi pendidikan non formal, pengalaman usaha tani, luas lahan dan serta kekosmopolitan mengenai frekuensi responden 1) berhubungan dengan orang luar desanya tentang usaha taninya dalam satu bulan terakhir, 2) bepergian ke tempat lain / desa enam bulan terakhir, 3) membaca media informasi yang berhubungan dengan pertanian satu bulan terakhir, 4) mendengarkan / melihat siaran radio / televise yang berhubungan dengan pertanian dalam satu bulan.

Frekuensi Pendidikan non Formal yaitu tingkat beberapa kalinya responden pernah mengikuti pelatihan-pelatihan tentang usaha tani (Yuniarsih dan Suwatno, 2008). Berdasarkan hasil penelitian sebagian besar anggota kelompok tani kopi arabika di Kecamatan Sangir merupakan petani yang pendidikan non formalnya termasuk dalam kelompok sedang, dimana petani tersebut telah pernah mengikuti penyuluhan pertanian berkaitan dengan komoditi kopi berkisar 1 sampai 2 kali.

\section{KESIMPULAN}

Berdasarkan hasil analisis dan pembahasan, maka dapat dibuat beberapa kesimpulan sebagai berikut:

1) Tingkat efektivitas kelompok tani kopi kopi arabika di kecamatan sangir kabupaten solok selatan dapat dilihat dari :

a. Produktvitas kelompok, dimana secara kesleuruhan dilaksanakan dengan cukup efektif sehingga terlihat bahwa anggota kelompok tani tersebut saling membantu anggotanya agar usaha taninya berkembang

b. Kepuasan anggota, secara keseluruhan dilaksanakan dengan cukup efektif sehingga terlihat bahwa anggota kelompok tani tersebut dapat menikmati peran mereka masing-masing sebagai anggota kelompok maupun peran dan fungsi kelompok dalam menunjang kebutuhan serta menyelesaikan masalah dalam berusaha tani kopi.

2) Berdasarkan hasil analisis ditemukan faktor internal kelompok berpengaruh positif dan signifikan terhadap efektivitas kelompok tani kopi arabika di Kecamatan Sangir Kabupaten Solok Selatan. Faktor internal kelompok yang dipergunakan adalah mengenai frekuensi pendidikan non formal, pengalaman usaha tani, luas lahan dan serta kekosmopolitan mengenai frekuensi responden 1) berhubungan dengan orang luar desanya tentang usaha taninya dalam satu bulan terakhir, 2) bepergian ke tempat lain / desa enam bulan terakhir, 3) membaca media informasi yang berhubungan dengan pertanian satu bulan terakhir, 4) mendengarkan / melihat siaran radio / televise yang berhubungan dengan pertanian dalam satu bulan.

3) Berdasarkan analisis diatas dikatakan hipotesis diterima sehingga dapat dikatakan faktor eksternal kelompok berpengaruh positif dan signifikan terhadap efektivitas kelompok tani kopi arabika di Kecamatan Sangir Kabupaten Solok Selatan. Faktor eksternal kelompok yang dipergunakan adalah mengenai ketersediaan informasi, ketersediaan saprodi, ketersediaan modal, intensitas penyuluhan, kepemimpinan ketua kelompok dan kemudahan pemasaran hasil. 


\section{SARAN}

Berdasarkan pengamatan peneliti, terdapat persoalan faktor internal kelompok yang perlu sangat untuk diperhatikan terutama oleh penyuluh pertanian di Kecamatan Sangir dari segi kekosmopolitan yang hanya dilakukan petani secara jarang atau kadang-kadang. Penyuluh pertanian harus melakukan perubahan terhadap keinginan kekosmopolitan petani yang tergabung dalam kelompok tani kopi arabika di Kecamatan Sangir mengenai keinginan petani untuk 1) berhubungan dengan orang luar desanya tentang usaha taninya dalam satu bulan terakhir, 2) bepergian ke tempat lain / desa enam bulan terakhir, 3) membaca media informasi yang berhubungan dengan pertanian satu bulan terakhir, 4) mendengarkan / melihat siaran radio / televise yang berhubungan dengan pertanian dalam satu bulan.

\section{DAFTAR PUSTAKA}

[1]. Kementan. 2017. Peraturan Menteri Pertanian. Tentang Pembinaan Kelembagaan Petani. Jakarta.

[2]. Kementan. 2018. Programa Penyuluhan Pertanian Nasional tahun 2018. Pusat Penyuluhan Pertanian. Badan Pusat Penyuluhan dan Pengembangan SDM Pertanian.

[3]. Kharisma, D dan Yuniningsih. 2017. Eefektivitas Organisasi dalam Penyelenggaraan Pelayanan Tanda Daftar Usaha Pariwisata (TDUP) Dinas Kebudayaan dan Pariwisata Kota Semarang. Jurnal Undip.Semarang Vol.6 No.2 Tahun 2017

[4]. Kusnadi, D. 2011. Metode Penyuluhan pertanian. Sekolah tinggi penyuluhan pertanian .Bogor . 6 hal.

[5]. Madarisa, F. 2014. Perspektif Sosiologi Pembangunan Agribisnis. Andalas University Press. 299 hal.

[6]. Madarisa, F. 2014. Teknik menyusun Usulan kegiatan Penyusunan Kegiatan Penyuluhan Pertanian. Andalas University Press.67 hal.

[7]. Karyani, Tuti dan Akbar, Ujang. 2016. Aksesibilitas Petani Mangga Gedong Gincu Terhadap Lembaga Keuangan Formal Dan Non-Formal Studi Kasus Gapoktan Sami Mulya Kecamatan Sedong Kabupaten Cirebon. Jurnal Agribisnis Terpadu Vol 9 No 2 Fakultas Pertanian Universitas Padjadjaran.

[8]. Mugi L. 2011. Dinamika Kelompok Dan Kemandirian Anggota Kelompok Tani Dalam Berusahatani Di Kecamatan Poncowarno Kabupaten Kebumen Propinsi Jawa Tengah. Tesis. Universitas Sebelas Maret Surakarta.

[9]. Mulyono, M. 1990. Penerapan Produktivitas dalam Organisasi. Penerbit Bumi Aksara. Jakarta. berkerjasama dengan Pusat antar Universitas-Studi Ekonomi Universitas Indonesia. 99 hal. 